\title{
Histamine neurons in the tuberomamillary nucleus: a whole center or distinct subpopulations?
}

\author{
Patrizio Blandina*, Leonardo Munari, Gustavo Provensi and Maria B. Passani
}

Dipartimento di Farmacologia Preclinica e Clinica, Universitá degli Studi di Firenze, Firenze, Italy

\section{Edited by:}

Pertti Panula, University of Helsinki, Finland

Reviewed by:

Christine E. Collins, Vanderbilt

University, USA

Helmut Haas, Heinrich-

Heine-Universität, Germany

Paul Chazot, Durham University, UK

${ }^{*}$ Correspondence:

Patrizio Blandina, Dipartimento di Farmacologia Preclinica e Clinica,

Universitá degli Studi di Firenze,

Viale G. Pieraccini 6,

50139 Firenze, Italy.

e-mail:patrizio.blandina@unifi.it
Histamine axons originate from a single source, the tuberomamillary nucleus (TMN) of the posterior hypothalamus, to innervate almost all central nervous system (CNS) regions. This feature, a compact cell group with widely distributed fibers, resembles that of other amine systems, such as noradrenaline or serotonin, and is consistent with a function for histamine over a host of physiological processes, including the regulation of the sleep-wake cycle, appetite, endocrine homeostasis, body temperature, pain perception, learning, memory, and emotion. An important question is whether these diverse physiological roles are served by different histamine neuronal subpopulation. While the histamine system is generally regarded as one single functional unit that provides histamine throughout the brain, evidence is beginning to accumulate in favor of heterogeneity of histamine neurons. The aim of this review is to summarize experimental evidence demonstrating that histamine neurons are heterogeneous, organized into functionally distinct circuits, impinging on different brain regions, and displaying selective control mechanisms. This could imply independent functions of subsets of histamine neurons according to their respective origin and terminal projections.

Keywords: $c$-fos, GABA $A-R$, GABA, histamine, $\mathrm{H}_{3}-\mathrm{R}$ antagonist, stress

\section{HISTAMINERGIC CELL BODIES ARE RESTRICTED TO THE TUBEROMAMILLARY NUCLEUS}

In neurons histamine is synthesized through decarboxylation of L-histidine by a specific histidine decarboxylase (E.C.4.1.1.22; HDC) (Green et al., 1987). In a comparable manner to the architecture of noradrenergic, dopaminergic, and serotonergic systems (Mason and Fibiger, 1979; Jacobs and Azmitia, 1992), histamine neurons are restricted to discrete cell clusters in the tuberomamillary nucleus (TMN) of the posterior hypothalamus (Watanabe et al., 1983; Panula et al., 1984), and send mostly unmyelinated axons to the entire central nervous system (CNS; Inagaki et al., 1988; Airaksinen et al., 1989). Catecholaminergic and serotonergic nuclei are clustered in distinct compartments with respect to projection fields, as sets of axons innervating separate brain regions originate from separate subgroups of noradrenergic (A1-A7), dopaminergic (A8-A17) and serotonergic (B1-B9) neurons (Mason and Fibiger, 1979; Jacobs and Azmitia, 1992). This pattern implies independent functions of sets of neurons according to their origin and terminal projections. This does not seem to be the case for the histaminergic system, as retrograde tracers injected into different CNS regions labeled histaminergic somata scattered throughout the TMN without a strict topographical pattern (Köhler et al., 1985; Inagaki et al., 1990). Moreover, histaminergic efferents present diffuse varicosities containing synaptic vesicles, but form synaptic contacts only infrequently (Takagi et al., 1986; Tohyama et al., 1991; Michelsen and Panula, 2002). This feature and the lack of a high-affinity uptake mechanism specific for histamine in the CNS suggest that histamine may diffuse from the site of release and has widespread effects, thus acting as a local hormone affecting not only neuronal, but also glial activity and blood vessel tone (Wada et al., 1991b). These features are compatible with reports of mismatches between distribution of histaminergic fibers and histaminergic receptors (Pillot et al., 2002; Haas et al., 2008), and have led to the concept that the histaminergic regulation of a wide range of brain functions, ranging from basic homeostasis such as sleep-wake rhythm, thermoregulation, food intake to emotions, learning, and memory (Haas et al., 2008; Passani et al., 2011), is achieved by the histaminergic system as a whole (Wada et al., 1991b).

\section{HISTAMINE IS INVOLVED IN MANY BRAIN FUNCTIONS}

Although several characteristics of histaminergic neurons emphasize their broad modulatory function, namely their diffuse projections as well as their capacity to release histamine at non-synaptic sites, other features, such as the existence of synaptic contacts and the demonstration of a tight temporal control, suggest that histamine can exert more discrete actions at specific brain loci (Inagaki et al., 1987; Haas et al., 2008). Indeed, the histaminergic system can implement many functions, including the arousal state, brain energy metabolism, locomotor activity, neuroendocrine, autonomic, and vestibular functions, feeding, drinking, sexual behavior, and analgesia, presumably by engaging independent subpopulations of histaminergic neurons according to the brain regions required for a particular behavioral outcome. Consistent with this hypothesis, heterogeneity within the histaminergic neuronal population in response to stress (Miklos and Kovacs, 2003) and pharmacological stimulations was recently reported (Blandina et al., 2010; Passani and Blandina, 2011). 


\section{HETEROGENEITY OF HISTAMINE NEURONS IN RESPONSE TO STRESS}

In the rat brain histaminergic, neuronal somata are grouped within the TMN in five clusters, E1-E5, each of which sends overlapping projections throughout the neuroaxis with a low level of topographical organization, and bridged by scattered neurons (Ericson et al., 1987; Inagaki et al., 1988, 1990). A similar pattern of distribution has been reported in the brains of other mammals and non-mammalian vertebrates (Wada et al., 1991a). Histamine release is a sensitive indicator of stress (Verdiere et al., 1977; Westerink et al., 2002). Indeed, restraint and/or metabolic stress are among the most potent activators of histamine neurons. Different types of stress (Miklos and Kovacs, 2003), as well as hypercapnic loading (Haxhiu et al., 2001) activated only selected subgroups of histaminergic neurons. These findings rely on the measurement of $c$-fos immunocytochemistry, a marker of cell activation, in histamine neurons identified with in situ hybridization of HDC mRNA. Under stress-free, basal conditions $c$-fos expression was detected in a negligible number of histamine neurons (less than 1\%) distributed uniformly in the TMN (Miklos and Kovacs, 2003). Following restraint, up to $36 \%$ of histamine neurons in E4 and E5 regions became $c$-fos positive, but significantly fewer, less than 10\%, were activated in E1, E2, or E3 regions (Miklos and Kovacs, 2003). Moreover, different types of stress, foot shock or insulin-induced hypoglycemia, activated E4 and E5 histamine neurons, but failed to induce any significant $c$-fos activation in the histamine neurons of the three remaining clusters. Therefore, stress-sensitive histamine neurons were detected in the rostral (E4-E5) subgroups rather than in the caudal ones (E1-E3), clearly indicating that histaminergic neurons of distinct TMN clusters are recruited in a stressor- and subgroup-specific manner (Miklos and Kovacs, 2003).

In line with the concept of heterogeneity of these neurons, only a subset of histaminergic neurons (E2) responded to hypercapnic stress $\left(\mathrm{CO}_{2}\right.$ exposure $)$ with an increase of $c$-fos expression (Haxhiu et al., 2001; Johnson et al., 2005). Consistently, recordings in rat brain slices revealed that acidification within the physiological range excited E2 neurons localized in the ventrolateral TMN. The excitation is mediated by both metabotropic glutamate receptors and acid sensing ion channels (ASICs; Yanovsky et al., 2012) that are expressed at significantly higher density in the ventrolateral TMN than in the medial part (Yanovsky et al., 2012). The functional significance of chemosensory traits in histaminergic neurons is not well known. However, it is expected that activation of histamine neurons by an increase in $\mathrm{CO}_{2}$ and/or $\mathrm{H}^{+}$may affect central respiratory drive through activation of neurons in the nucleus tractus solitarius, a region displaying a dense network of histaminergic fibers (Airaksinen and Panula, 1988; Airaksinen et al., 1989).

\section{HETEROGENEITY OF HISTAMINE NEURONS IN RESPONSE TO GABA AND GLYCINE}

Heterogeneity within the histaminergic neuron population was shown also using a different approach. It is well established that the activity of histamine neurons is closely associated with the behavioral state: in behaving cats, rats, and mice, the firing is more variable during waking and absent upon drowsiness and during sleep. This is the most wake-selective firing pattern identified in the brain to date (Lin, 2000; Lin et al., 2011). Sleep-active, GABAergic neurons in the ventrolateral preoptic nucleus (VLPO) provide a major input to the TMN, and may play a key role in silencing the ascending histaminergic arousal system during sleep (Sherin et al., 1998). Interestingly, GABA release in the posterior hypothalamus increased during SWS, and microinjection of the $\mathrm{GABA}_{\mathrm{A}}$-receptor $\left(\mathrm{GABA}_{\mathrm{A}}-\mathrm{R}\right)$ agonist muscimol, into the same area increased SWS time (Nitz and Siegel, 1996). Hence, GABA release in the posterior hypothalamus inhibits directly histaminergic cells firing rate (Yang and Hatton, 1997), thereby facilitating SWS, whereas $\mathrm{GABA}_{\mathrm{A}}-\mathrm{R}$ inhibition increases significantly the release of histamine from the TMN, as measured with microdialysis (Cenni et al., 2006). Electrophysiological studies using whole-cell recording identified two subpopulations among histamine neurons isolated from the TMN according to their sensitivity to GABA (Sergeeva et al., 2002), with GABA concentrations for threshold and maximal responses ranging between 0.5 and $5 \mu \mathrm{M}$ in one subpopulation, and between 50 and $500 \mu \mathrm{M}$ in the other one (Sergeeva et al., 2002). GABA responses were completely blocked by gabazine, a selective antagonist of $\mathrm{GABA}_{\mathrm{A}}-\mathrm{R}$ (Sergeeva et al., 2002). This receptor is a protein complex assembled from a family of 19 homologous subunit gene products that form mostly hetero-oligomeric pentamers. The major isoforms contain alpha, beta, and gamma subunits and show differential sensitivity to GABA, to modulators like steroids, to physiological regulation, and to disease processes (Olsen and Sieghart, 2009). Sergeeva and coworkers (Sergeeva et al., 2002), using whole-cell recording and single cell RT-PCR from isolated rat histamine neurones, characterized $\mathrm{GABA}_{\mathrm{A}}-\mathrm{R}$ evoked currents and correlated them with the expression patterns of $12 \mathrm{GABA}_{\mathrm{A}}-\mathrm{R}$ subunits. They identified three different groups of histamine neurons on the basis of their gamma subunits expression. The occurrence of each gamma subunit was correlated with GABA EC 50 . The group expressing both gamma1 and gamma2 subunits displayed a high sensitivity to GABA, whereas the group expressing only the gamma2 subunit displayed a low sensitivity. Histaminergic neurons are also heterogeneous with respect to their sensitivity to glycine that correlates with their size. Indeed, the maximal glycine response $(1 \mathrm{mM})$ in histaminergic cells with larger somata $(25 \mu)$ was about half of the maximal GABA response whereas in the cells with a smaller soma size $(19.5 \mu)$ the glycine response was absent or very small (Sergeeva et al., 2001).

\section{HISTAMINE NEURONS ESTABLISH FUNCTIONALLY DISTINCT PATHWAYS ACCORDING TO THEIR TERMINAL PROJECTIONS}

In our laboratory we addressed the question of whether histaminergic neurons are organized into distinct functional circuits impinging on different brain regions. We used the double-probe microdialysis technique in freely moving animals, which provides a powerful means for defining the dynamics regulating histamine release in discrete brain regions. Rats were implanted with one probe in the TMN, to deliver drugs and measure histamine release locally, and another probe to measure histamine release from histaminergic projection areas such as the prefrontal cortex, the nucleus basalis magnocellularis (NBM), the nucleus accumbens (NAcc) or the dorsal striatum. By applying compounds targeting 
receptors expressed on histamine neurons and measuring histamine output in different brain areas, we demonstrated that the same drug influenced differently the release of histamine from distinct brain regions. Bicuculline, a $\mathrm{GABA}_{\mathrm{A}}-\mathrm{R}$ antagonist, acts directly onto histaminergic neurons to augment cell firing (Haas et al., 2008). We found that intra-hypothalamic perfusion of bicuculline increased histamine release from the TMN, the NAcc and the prefrontal cortex, but not from the striatum (Giannoni et al., 2009) (Table 1). Different subunit composition and stoichiometry of $\mathrm{GABA}_{\mathrm{A}}$-Rs among histaminergic neurons (Sergeeva et al., 2002, 2005) may account for these results. It is worth noting that functional heterogeneity of responses to bicuculline among histaminergic neurons relates to TMN neurons heterogeneity with respect to projection fields. Also, responses to histamine 3 receptor $\left(\mathrm{H}_{3}-\mathrm{R}\right)$ antagonists differentiate histaminergic neurons according to their projection areas. When applied to the rat TMN, $\mathrm{H}_{3}-\mathrm{R}$ antagonists, such as thioperamide or the more recently synthesized, non-imidazole compounds as GSK189254, invariably augmented histamine release from the TMN, from the prefrontal cortex and from the NBM, but not from the NAcc, nor the striatum (Giannoni et al., 2009, 2010) (Table 1). The $\mathrm{H}_{3}-\mathrm{R}$ is present on presynaptic terminals and varicosities of histaminergic axons, where it moderates histamine synthesis and release (Arrang et al., 1983, 1985). $\mathrm{H}_{3}$-Rs are also located on histaminergic neuronal somata, and provide a tonic inhibition (Haas and Panula, 2003) by modulating inward $\mathrm{Ca}^{++}$currents (Reiner, 1987; Takeshita et al., 1998; Stevens et al., 2001). Therefore, blockade of somatic and presynaptic $\mathrm{H}_{3}$-autoreceptors increase cell firing (Haas and Panula, 2003) and augment histamine levels in the synaptic cleft. In the TMN, histamine is released from short projections that form extensive axonal arborizations in the posterior hypothalamus. Thioperamide or GSK-189254 were applied locally through the microdialysis probe to the TMN (Giannoni et al., 2009, 2010), hence histamine output increased as a consequence of both somatic and presynaptic $\mathrm{H}_{3}$-autoreceptors blockade, although the participation of only one component cannot be excluded. Thioperamide or GSK-189254, applied locally into the TMN, significantly increased histamine release also from the prefrontal cortex, and the NBM, but histamine levels remained stable in the dorsal striatum and NAcc. Increases in the prefrontal cortex and NBM were likely due to discharge potentiation of histamine neurons sending efferents to these regions, in a way similar to the effects of TMN perfusion with prostaglandin $\mathrm{E}_{2}$ (Huang et al., 2003), or Orexin-A (Huang et al., 2001). On the other hand, the lack of increase in histamine release during TMN perfusion with $\mathrm{H}_{3}-\mathrm{R}$ antagonists observed in the dorsal striatum and NAcc, despite the fact that these brain areas receive histaminergic innervation (Panula et al., 1989), indicates that histaminergic neurons projecting to these regions are insensitive to $\mathrm{H}_{3}-\mathrm{R}$ blockade. We further demonstrated that histaminergic neurons are not a homogenous neuronal population using cannabinoid receptor 1 (CB1) agonists. Administration of methanandamide (mAEA) or ACEA in the TMN facilitated histamine release from the TMN itself, from the NBM and striatum as well (Cenni et al., 2006). However, perfusion of the posterior hypothalamus with mAEA did not change significantly histamine release from the perirhinal cortex (Passani et al., 2007; Table 1) despite the profuse histaminergic innervation of this region (Panula et al., 1989) and the presence of histaminergic receptors (Pillot et al., 2002).

Spatial segregation due to probe localization does not explain the lack of response, as retrograde tracing with dye injections into the striatum or prefrontal cortex showed that most histaminergic somata are within the medial part of the ventral TMN (Köhler et al., 1985). This proximity suggests that histaminergic somata projecting to the striatum and prefrontal cortex had the same exposure to $\mathrm{H}_{3}-\mathrm{R}$ antagonists, but were not affected in the same way. In conclusion, $\mathrm{H}_{3}-\mathrm{R}$ antagonists may discriminate groups of histaminergic neurons impinging on different brain regions, thus suggesting that these neurons are organized into functionally distinct circuits that influence different brain regions, and display selective control mechanisms. In keeping with these results, activation of $c$-fos after GSK189254 administration occurred in cortical areas and the TMN, but not in striatum (Medhurst et al., 2007). To explore the local effects of $\mathrm{H}_{3}$ - $\mathrm{R}$ blockade in the histaminergic projection areas, single-probe microdialysis experiments were performed. Local perfusion with $\mathrm{H}_{3}$ - $\mathrm{R}$ antagonists in the NBM or prefrontal cortex augmented significantly histamine release within these regions, an effect that can be explained by blockade of local $\mathrm{H}_{3}$-autoreceptors. The same drugs administered locally to the striatum or NAcc did not modify histamine release, thus indicating that the whole somatodendritic domain of histaminergic neurons projecting to these regions is insensitive to $\mathrm{H}_{3}-\mathrm{R}$ antagonists. Accordingly, lesion experiments indicate that the vast majority of $\mathrm{H}_{3}$-Rs in the NAcc and striatum are not associated with histaminergic fibers (Pollard et al., 1993), which is consistent with high densities of $\mathrm{H}_{3}-\mathrm{R}$

Table 1 | Influence of drug administration into the TMN on histamine release from different brain areas of freely moving rats.

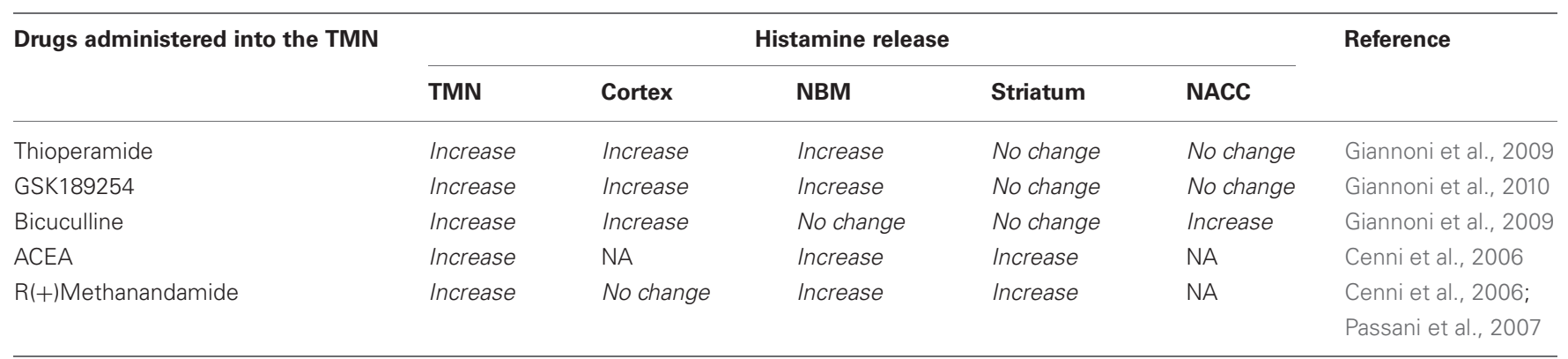

NA, not available 

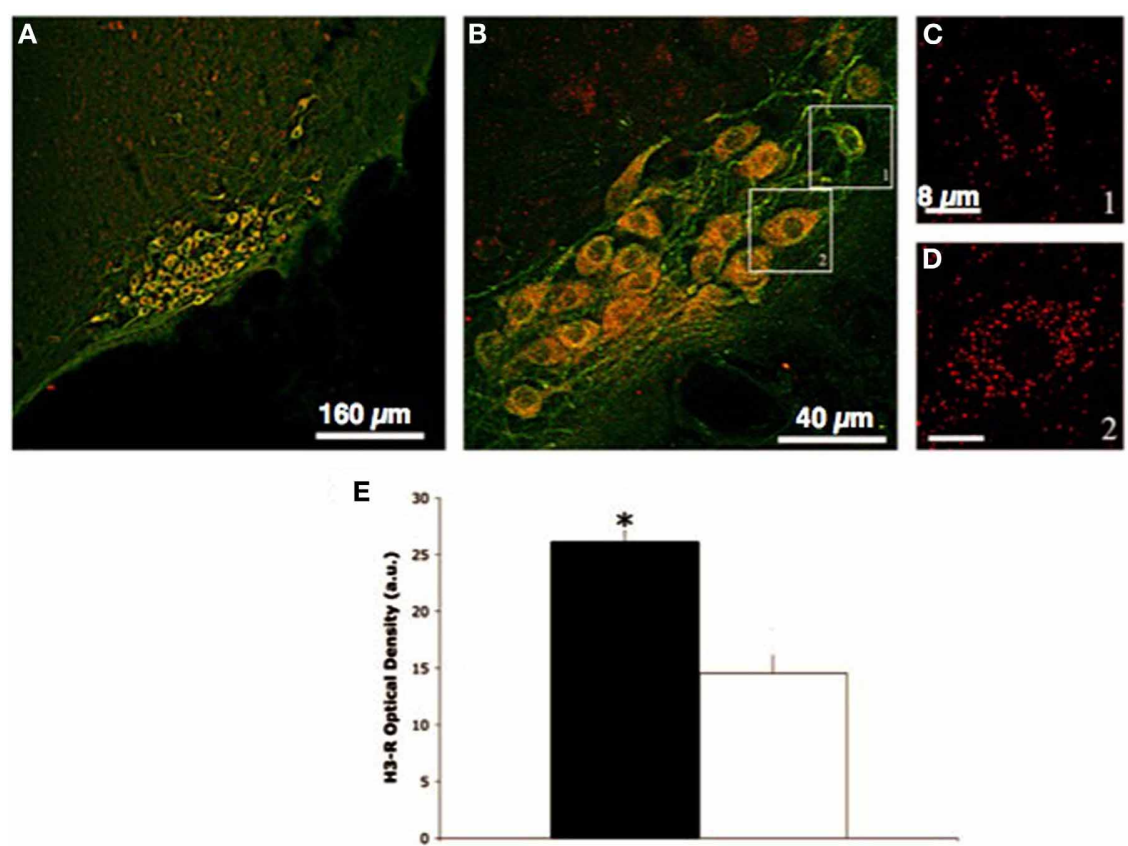

FIGURE 1 | Distribution of $\mathrm{H}_{3}-\mathrm{R}$ on TMN histaminergic neurons. (A,B) HDC-positive cells in the E2-E3 subdivision of the TMN showing $\mathrm{H}_{3}-\mathrm{R}$ fluorescence; (C,D) high resolution z-projections of $\mathrm{H}_{3}-\mathrm{R}$ expression in the HDC-positive neurons selected in (B); (E) Average intensity of colocalised signals. Analysis of immunocolocalization density was carried out on regions of interest (ROI) of identical area (576 pixels), identified on randomly chosen
HDC-positive neurons that where entirely within the thickness of the specimen and were not overlapping. An arbitrary level was set at an optical density value of 20 arbitrary units. Shown are means \pm SEM, $* P<0.05$ (unpaired $t$-test). Observations were repeated in three rats with similar results. Calibration bar; (A) $160 \mathrm{~mm}$; (B) $40 \mathrm{~mm}$; (C,D) $8 \mathrm{~mm}$. Modified from Giannoni et al. (2009).
mRNAs levels in the same regions (Chazot et al., 2001; Cannon et al., 2007), and suggests a postsynaptic localization of these receptors. Indeed, $\mathrm{H}_{3}-\mathrm{R}$ are not restricted to histaminergic neurons (Pollard et al., 1993), and they act also as heteroreceptors modulating the release of neurotransmitters such as acetylcholine (ACh), dopamine, glutamate, noradrenaline, or serotonin from brain regions crucial for the maintenance of alertness or the storage of information (Passani et al., 2004; Haas et al., 2008). Although it is generally assumed that all histaminergic neurons express $\mathrm{H}_{3}-\mathrm{R}$, several isoforms displaying strong differences have been described (Bongers et al., 2007). Hence, in vivo insensitivity to $\mathrm{H}_{3}-\mathrm{R}$ antagonists may depend on high expression of particular isoforms. In this regard, another observation is intriguing. The distribution of $\mathrm{H}_{3}-\mathrm{R}$ on TMN neurons was examined by performing double immunofluorescence labeling with a combination of anti- $\mathrm{H}_{3}-\mathrm{R}$ and anti-HDC antibodies (Giannoni et al., 2009). Polyclonal $\mathrm{H}_{3}-\mathrm{R}$ antibodies are directed against residues 349-358 of human and rat $\mathrm{H}_{3}-\mathrm{R}$ and were previously validated (Chazot et al., 2001; Cannon et al., 2007). In the posterior lateral hypothalamus, both HDC-positive and -negative cells show $\mathrm{H}_{3}-\mathrm{R}$ immunostaining (Figure 1) The density of $\mathrm{H}_{3}-\mathrm{R}$ immunolabeling was very high in the cytoplasm and on cell membranes of some HDC-positive cell and very low in others, as revealed by confocal microscopy (for immunocytochemical procedures see Cenni et al., 2006). A quantitative analysis was carried out counting the number of pixels with colocalized signal on randomly chosen neurons in hypothalamic brain sections from three rat brains. Setting at 20 the optical density expressed in arbitrary units, two histaminergic neuronal populations that differed significantly for $\mathrm{H}_{3}-\mathrm{R}$ expression levels were found (Figure 1). Since the magnitude of neuronal responses to extracellular signals may depend, at least in part on membrane receptor density, one might envisage that HDC-positive cells displaying very low levels of $\mathrm{H}_{3}-\mathrm{R}$ immunoreactivity are those innervating the NAcc or striatum.

\section{CONCLUSIONS}

Much has been learned over the past 25 years about the role of histamine as a neurotransmitter. Histamine is found in TMN neurons that are active during wakefulness and exert multiple functions. Indeed, histamine has a major role in maintenance of arousal and contributes to modulation of circadian rhythms, energy, and endocrine homeostasis, motor behavior, and cognition. The extent to which these diverse physiological roles are served by different functional histamine systems is unclear, however, there is much experimental evidence suggesting that the histaminergic system is organized into distinct pathways modulated by selective mechanisms. This could imply independent functions of subsets of histaminergic neurons according to their respective origin and terminal projections. Consequences could be relevant for the development of specific compounds that affect only subsets of HA cells, thus increasing the target specificity.

\section{ACKNOWLEDGMENTS}

This research was supported by Universitá di Firenze funds, PRIN 2007 (519MIUR068), and Compagnia di San Paolo-Torino (I). 


\section{REFERENCES}

Airaksinen, M. S., Flugge, G., Fuchs, E., and Panula, P. (1989). Histaminergic system in the tree shrew brain. J. Comp. Neurol. 286, 289-310.

Airaksinen, M. S., and Panula, P. (1988). The histaminergic system in the guinea pig central nervous system: immunocytochemical mapping study using an antiserum against histamine. J. Comp. Neurol. 273, 163-186.

Arrang, J. M., Garbarg, M., and Schwartz, J. C. (1983). Autoinhibition of brain histamine release mediated by a novel class $\left(\mathrm{H}_{3}\right)$ of histamine receptors. Nature 302, 832-837.

Arrang, J. M., Garbarg, M., and Schwartz, J. C. (1985). Autoregulation of histamine release in brain by presynaptic $\mathrm{H}_{3}$-receptors. Neuroscience 15 , 553-562.

Blandina, P., Munari, L., Giannoni, P., Mariottini, C., and Passani, M. B. (2010). Histamine neuronal system as therapeutic target for the treatment of cognitive disorders. Future Neurol. 5, 543-555.

Bongers, G., Bakker, R. A., and Leurs, R. (2007). Molecular aspects of the histamine $\mathrm{H}_{3}$ receptor. Biochem. Pharmacol. 73, 1195-1204.

Cannon, K. E., Chazot, P. L., Hann, V., Shenton, F., Hough, L. B., and Rice, F. L. (2007). Immunohistochemical localization of histamine $\mathrm{H}_{3}$ receptors in rodent skin, dorsal root ganglia, superior cervical ganglia, and spinal cord: potential antinociceptive targets. Pain 129, 76-92.

Cenni, G., Blandina, P., Mackie, K., Nosi, D., Formigli, L., Giannoni, P., Ballini, C., Dellacorte, L., Mannaioni, P. F., and Passani, M. B. (2006). Differential effect of cannabinoid agonists and endocannabinoids on histamine release from distinct regions of the rat brain. Eur. J. Neurosci. 24, 1633-1644.

Chazot, P. L., Hann, V., Wilson, C., Lees, G., and Thompson, C. L. (2001). Immunological identification of the mammalian $\mathrm{H}_{3}$ histamine receptor in the mouse brain. Neuroreport 12, 259-262.

Ericson, H., Watanabe, T., and Köhler, C. (1987). Morphological analysis of the tuberomammillary nucleus of the rat brain: delineation of subgroups with antibody against Lhistidine decarboxylase as a marker. J. Comp. Neurol. 263, 1-24.

Giannoni, P., Medhurst, A. D., Passani, M. B., Giovannini, M. G., Ballini,
C., Dellacorte, L., and Blandina, P. (2010). Regional differential effects of the novel histamine $\mathrm{H}_{3}$ receptor antagonist 6-[(3cyclobutyl-2,3,4,5-tetrahydro- $1 \mathrm{H}$ 3-benzazepin-7-yl)oxy]-N-methyl3-pyridinecarboxamide hydrochloride (GSK189254) on histamine release in the central nervous system of freely moving rats. J. Pharmacol. Exp. Ther. 332, 164-172.

Giannoni, P., Passani, M. B., Nosi, D., Chazot, P. L., Shenton, F. C., Medhurst, A. D., Munari, L., and Blandina, P. (2009). Heterogeneity of histaminergic neurons in the tuberomammillary nucleus of the rat. Eur. J. Neurosci. 29, 2363-2374.

Green, J. P., Prell, G. D., Khandelwal, J. K., and Blandina, P. (1987). Aspects of histamine metabolism. Agents Actions 22, 1-15.

Haas, H., and Panula, P. (2003). The role of histamine and the tuberomamillary nucleus in the nervous system. Nat. Rev. Neurosci. 4, 121-130.

Haas, H., Sergeeva, O., and Selbach, O. (2008). Histamine in the nervous system. Physiol. Rev. 88, 1183-1241.

Haxhiu, M. A., Tolentino-Silva, F., Pete, G., Kc, P., and Mack, S. O. (2001). Monoaminergic neurons, chemosensation and arousal. Respir. Physiol. 129, 191-209.

Huang, Z.-L., Qu, W.-M., Li, W.-D., Mochizuki, T., Eguchi, N., Watanabe, T., Urade, Y., and Hayaishi, O. (2001). Arousal effect of orexin A depends on activation of the histaminergic system. Proc. Natl. Acad. Sci. U.S.A. 98, 9965-9970.

Huang, Z.-L., Sato, Y., Mochizuki, T., Okada, T., Qu, W.-M., Yamatodani, A., Urade, Y., and Hayaishi, O. (2003). Prostaglandin E2 activates the histaminergic system via the EP4 receptor to induce wakefulness in rats. J. Neurosci. 23, 5975-5983.

Inagaki, N., Toda, K., Taniuchi, I., Panula, P., Yamatodani, A., Tohyama, M., Watanabe, T., and Wada, H. (1990). An analysis of histaminergic efferents of the tuberomammillary nucleus to the medial preoptic area and inferior colliculus of the rat. Exp. Brain Res. 80, 374-380.

Inagaki, N., Yamatodani, A., AndoYamamoto, M., Tohyama, M., Watanabe, T., and Wada, H. (1988). Organization of histaminergic fibers in the rat brain. J. Comp. Neurol. 273, 283-300.

Inagaki, N., Yamatodani, A., Shinoda, K., Shiotani, Y., Tohyama, M., Watanabe, T., and Wada, H. (1987). The histaminergic innervation of the mesencephalic nucleus of trigeminal nerve in the rat brain: a light and electron microscopic study. Brain Res. 418, 388-391.

Jacobs, B. L., and Azmitia, E. C. (1992). Structure and function of the brain serotonin system. Physiol. Rev. 72, 165-229.

Johnson, P. L., Moratalla, R., Lightman, S. L., and Lowry, C. A. (2005). Are tuberomammillary histaminergic neurons involved in $\mathrm{CO}_{2}$ mediated arousal? Exp. Neurol. 193, 228-233.

Köhler, C., Swanson, L., Haglund, L., and Wu, J. (1985). The cytoarchitecture, histochemistry and projections of the tuberomammillary nucleus in the rat. Neuroscience 16, 85-110.

Lin, J. S. (2000). Brain structures and mechanisms involved in the control of cortical activation and wakefulness, with emphasis on the posterior hypothalamus and histaminergic neurons. Sleep Med. Rev. 4, 471-503.

Lin, J. S., Anaclet, C., Sergeeva, O. A., and Haas, H. L. (2011). The waking brain: an update. Cell. Mol. Life Sci. 68, 2499-2512.

Mason, S. T., and Fibiger, H. C. (1979). Regional topography within noradrenergic locus coeruleus as revealed by retrograde transport of horseradish peroxidase. J. Comp. Neurol. 187, 703-724.

Medhurst, A. D., Atkins, A. R., Beresford, I. J., Brackenborough, K., Briggs, M. A., Calver, A. R., Cilia, J., Cluderay, J. E., Crook, B., Davis, J. B., Davis, R. K., Davis, R. P., Dawson, L. A., Foley, A. G., Gartlon, J., Gonzalez, M. I., Heslop, T., Hirst, W. D., Jennings, C., Jones, D. N., Lacroix, L. P., Martyn, A., Ociepka, S., Ray, A., Regan, C. M., Roberts, J. C., Schogger, J., Southam, E., Stean, T. O., Trail, B. K., Upton, N., Wadsworth, G., Wald, J. A., White, T., Witherington, J., Woolley, M. L., Worby, A., and Wilson, D. M. (2007). GSK189254, a novel $\mathrm{H}_{3}$ receptor antagonist that binds to histamine $\mathrm{H}_{3}$ receptors in Alzheimer's disease brain and improves cognitive performance in preclinical models. J. Pharmacol. Exp. Ther. 321, 1032-1045.

Michelsen, K., and Panula, P. (2002). Subcellular distribution of histamine in mouse brain neurons. Inflamm. Res. 51 (Suppl. 1), S46-S48.

Miklos, I. H., and Kovacs, K. J. (2003). Functional heterogeneity of the responses of histaminergic neuron subpopulations to various stress challenges. Eur. J. Neurosci. 13, 3069-3079.

Nitz, D., and Siegel, J. (1996). GABA release in posterior hypothalamus across sleep-wake cycle. Am. J. Physiol. 271, R1707-R1712.

Olsen, R., and Sieghart, W. (2009). $\mathrm{GABA}_{\mathrm{A}}$ receptors: subtypes provide diversity of function and pharmacology. Neuropharmacology 56, 141-148.

Panula, P., Pirvola, U., Auvinen, S., and Airaksinen, M. S. (1989). Histamine-immunoreactive nerve fibers in the rat brain. Neuroscience 28, 585-610.

Panula, P., Yang, H. Y., and Costa, E. (1984). Histamine-containing neurons in the rat hypothalamus. Proc. Natl. Acad. Sci. U.S.A. 81, 2572-2576.

Passani, M. B., and Blandina, P. (2011). Histamine $\mathrm{H}_{3}$ receptors in the CNS as targets for therapeutic intervention. Trends Pharmacol. Sci. 32, 242-249.

Passani, M. B., Blandina, P., and Torrealba, F. (2011). The histamine $\mathrm{H}_{3}$ receptor and eating behavior. J. Pharmacol. Exp. Ther. 336, 24-29.

Passani, M. B., Giannoni, P., Bucherelli, C., Baldi, E., and Blandina, P. (2007). Histamine in the brain: beyond sleep and memory. Biochem. Pharmacol. 73, 1113-1122.

Passani, M. B., Lin, J.-S., Hancock, A., Crochet, S., and Blandina, P. (2004). The histamine $\mathrm{H}_{3}$ receptor as a novel therapeutic target for cognitive and sleep disorders. Trends Pharmacol. Sci. 25, 618-625.

Pillot, C., Heron, A., Cochois, V., Tardivel-Lacombe, J., Ligneau, X., Schwartz, J.-C., and Arrang, J.-M. (2002). A detailed mapping of the histamine $\mathrm{H}_{3}$ receptor and its gene transcript in rat brain. Neuroscience 114, 173-193.

Pollard, H., Moreau, J., Arrang, J. M., and Schwartz, J.-C. (1993). A detailed autoradiographic mapping of histamine $\mathrm{H}_{3}$ receptors in rat brain areas. Neuroscience 52, 169-189.

Reiner, P. B. (1987). Electrophysiological properties of cortically projecting histamine neurons of rat hypothalamus. Neurosci. Lett. 73, 43-47.

Sergeeva, O. A., Andreeva, N., Garret, M., Scherer, A., and Haas, H. L. (2005). Pharmacological properties of $\mathrm{GABA}_{\mathrm{A}}$ receptors in rat hypothalamic neurons expressing the epsilon-subunit. J. Neurosci. 25, 88-95.

Sergeeva, O. A., Eriksson, K. S., and Haas, H. L. (2001). Glycine receptor 
mediated responses in rat histaminergic neurons. Neurosci. Lett. 300, 5-8.

Sergeeva, O. A., Eriksson, K. S., Sharonova, I. N., Vorobjev, V. S., and Haas, H. L. (2002). GABA(A) receptor heterogeneity in histaminergic neurons. Eur. J. Neurosci. 16, 1472-1482.

Sherin, J., Elmquist, J., Torrealba, F., and Saper, C. (1998). Innervation of tuberomammilary neurons by Gabaergic and galaninergic neurons in the ventrolateral preoptic nucleus of the rat. J. Neurosci. 18, 4705-4721.

Stevens, D. R., Eriksson, K. S., Brown, R. E., and Haas, H. L. (2001). The mechanism of spontaneous firing in histamine neurons. Behav. Brain Res. 124, 105-112.

Takagi, H., Morishima, Y., Matsuyama, T., Hayashi, H., Watanabe, T., and Wada, H. (1986). Histaminergic axons in the neostriatum and cerebral cortex of the rat: a correlated light and electron microscope immunocytochemical study using histidine decarboxylase as a marker. Brain Res. 364, 114-123.
Takeshita, Y., Watanabe, T., Sakata, T., Munakata, M., Ishibashi, H., and Akaike, N. (1998). Histamine modulates high-voltage-activated calcium channels in neurons dissociated from the rat tuberomammillary nucleus. Neuroscience 87, 797-805.

Tohyama, M., Tamiya, R., Inagaki, N., and Tagaki, H. (1991). "Morphology of histaminergic neurons with histidine decarboxylase as a marker," in Histaminergic Neurons: Morphology and Function, eds T. Watanabe and $\mathrm{H}$. Wada (Boca Raton, FL: CRC Press), 107-126.

Verdiere, M., Rose, C., and Schwartz, J.-C. (1977). Turnover of cerebral histamine in a stressful situation. Brain Res. 129, 107-119.

Wada, H., Inagaki, N., Itowi, N., and Yamatodani, A. (1991a). Histaminergic neuron system in the brain: distribution and possible functions. Brain Res. Bull. 27, 367-370.

Wada, H., Inagaki, N., Yamatodani, A., and Watanabe, T. (1991b). Is the histaminergic neuron system a regulatory center for wholebrain activity? Trends Neurosci. 14, 415-418.

Watanabe, T., Taguchi, Y., Hayashi, H., Tanaka, J., Shiosaka, S., Tohyama, M., Kubota, H., Terano, Y., and Wada, H. (1983). Evidence for the presence of a histaminergic neuron system in the rat brain: an immunohistochemical analysis. Neurosci. Lett. 39, 249-254.

Westerink, B., Cremers, T., Vries, J. D., Liefers, H., Tran, N., and Boer, P. D. (2002). Evidence for activation of histamine $\mathrm{H}_{3}$ autoreceptors during handling stress in the prefrontal cortex of the rat. Synapse 15 , 238-243.

Yang, Q. Z., and Hatton, G. I. (1997). Electrophysiology of excitatory and inhibitory afferents to rat histaminergic tuberomammillary nucleus neurons from hypothalamic and forebrain sites. Brain Res. 773, 162-172.

Yanovsky, Y., Zigman, J. M., Kernder, A., Bein, A., Sakata, I., OsborneLawrence, S., Haas, H. L., and Sergeeva, O. A. (2012). Proton- and ammonium-sensing by histaminergic neurons controlling wakefulness. Front. Syst. Neurosci. 6:23. doi: 10.3389/fnsys.2012.00023

Conflict of Interest Statement: The authors declare that the research was conducted in the absence of any commercial or financial relationships that could be construed as a potential conflict of interest.

Received: 01 February 2012; accepted: 16 April 2012; published online: 04 May 2012.

Citation: Blandina P, Munari L, Provensi $G$, and Passani MB (2012) Histamine neurons in the tuberomamillary nucleus: a whole center or distinct subpopulations?. Front. Syst. Neurosci. 6:33. doi: 10.3389/fnsys.2012.00033

Copyright (C) 2012 Blandina, Munari, Provensi and Passani. This is an openaccess article distributed under the terms of the Creative Commons Attribution Non Commercial License, which permits non-commercial use, distribution, and reproduction in other forums, provided the original authors and source are credited. 